\title{
Prosodic sensitivity and reading fluency of musicians and non-musicians
}

\author{
Anja L. Obergfell ${ }^{1} \mathbb{D} \cdot$ Barbara M. Schmidt ${ }^{1}$. Prisca Stenneken ${ }^{1}$. \\ Sonja K. Wittemann ${ }^{1} \cdot$ Alfred Schabmann $^{1}$
}

Accepted: 28 September 2020 / Published online: 19 October 2020

(c) The Author(s) 2020

\begin{abstract}
This study investigates the effects of prosodic sensitivity on reading. Highly capable adult musicians (i.e., persons with potentially excellent prosodic skills) and nonmusicians were compared in terms of prosodic sensitivity and reading. Furthermore, the study examines possible reciprocal effects of prosodic sensitivity and reading. Sixty native German-speaking university students, musicians $(n=30)$ and nonmusicians $(n=30)$, completed three measures of prosodic sensitivity on the sentence level. In addition, word and nonword reading were tested. To check for possible reciprocal effects of prosodic sensitivity and reading, groups of musicians and nonmusicians matched on the reading level as well as the prosodic sensitivity level were compared. The results showed that musicians outperformed non-musicians in two of the three prosodic sensitivity measures and both reading measures. Considering subgroup analysis this seems to indicate a non-reciprocal effect of prosodic sensitivity on reading. Moreover, when controlling for phonological awareness, prosodic sensitivity showed a unique effect on reading in the whole sample. Based on the results, we argue that good prosodic sensitivity can facilitate reading performance.
\end{abstract}

Keywords Basic auditory processing $\cdot$ Musicians $\cdot$ Prosodic sensitivity $\cdot$ Reading

\section{Introduction}

There is increasing interest in the relationship between prosodic sensitivity (PS) and reading. Empirical evidence for the influence of PS on reading comes from studies comparing persons with and without dyslexia (Cuetos, Martínez-García, \& Suárez-Coalla, 2018; Goswami, Gerson, \& Astruc, 2010; Goswami et al., 2013; Leong, Hämäläinen, Soltész, \& Goswami, 2011) as well as correlational studies

Anja L. Obergfell

anja.obergfell@uni-koeln.de

1 Department of Special Education and Rehabilitation, Faculty of Human Sciences, University of Cologne, Klosterstr. 79b, 50931 Cologne, Germany 
(Arciuli, 2017; Clin, Wade-Woolley, \& Heggie, 2009; Defior, Gutiérrez-Palma, \& Cano-Marín, 2012; Goswami et al., 2010; Holliman et al., 2017; Holliman, Wood, \& Sheehy, 2008, 2010a, 2010b; Jarmulowicz, Taran, \& Hay, 2007). However, some studies report an effect only for a subsample of a certain age (Gutiérrez-Palma, Defior, Jiménez-Fernández, Serrano, \& González-Trujillo, 2016; Lin, Wang, Newman, \& Li, 2018) or a certain type of reading outcome (Wade-Woolley, 2016; Whalley \& Hansen, 2006). Furthermore, several correlational studies could not confirm the influence of PS on reading (Deacon, Holliman, Dobson, \& Harrison, 2018; Kim \& Petscher, 2016; Schmidt, Breuer-Küppers, Göntgen, \& Schabmann, 2016). As the results of correlational studies are inconsistent, the present study aims to examine the PS-reading relationship with a novel approach. Alongside existing correlational studies and examinations of an extreme group (dyslexics), a third way to examine the PS-reading relationship involves another extreme group, namely subjects with potentially excellent prosodic skills. As PS is affected by music-related, non-linguistic auditory processing skills (Goswami et al., 2010, 2013; Richards \& Goswami, 2015), comparing a sample of musicians to non-musicians is a good way to further clarify the effects of PS on reading. In this paper, we compare PS and reading in a sample of adult musicians and non-musicians and try to clarify the possibility of a reciprocal influence of PS and reading.

\section{The effect of prosodic sensitivity on reading}

PS refers to sensitivity to the prosodic components of speech. According to Harrison and Wood (2016), three different components of prosody must be distinguished: variation in tone amplitude (stress; i.e., variations in loudness between syllables and words), variation in tone frequency (intonation; rising and falling pitch in speech), and the timing of words and syllables ("relative duration of syllables and vowel length"; Harrison \& Wood, 2016, p. 91).

Efficient reading relies on a system enabling quick and stable access to words (Brown \& Loosemore, 1994; Jackson \& Coltheart, 2001). Although the exact mechanism is still not clear, it is conceivable that prosodic information might (combined with other information) serve as an additional hint for the reader when retrieving words. In the literature, several possible causal chains are discussed:

1. PS facilitates phoneme identification: This explanation refers to the fact that it easier to identify phonemes (particularly vowels) in stressed than in unstressed syllables, which often consist of vocals with reduced quality, i.e., schwa (Chiat, 1983; cf. Holliman, Wood, \& Sheehy, 2012; Wood, Wade-Woolley, \& Holliman, 2009).

2. PS facilitates onset-rime boundary detection: Amplitude peak in spoken language is connected to the position and quality of the vowel sound in the word (Goswami, 2003; Scott, 1998). Therefore, persons with better sensitivity for amplitude 
changes in spoken language might find it easier to recognize onset-rime boundaries, which is crucial for reading (Goswami et al., 2002; cf. Holliman et al., 2012; Wood et al., 2009).

3. PS facilitates the development of vocabulary: PS might facilitate the identification of word boundaries. This might particularly be the case for stress-timed languages, in which most stress is on the first syllable (Cutler \& Norris, 1988). This in turn affects both rhyme sensitivity and morphological awareness, which facilitates word reading (cf. Holliman et al., 2012, 2014; Holliman, 2016).

4. PS supports morphological clarity: PS might avoid conflicts in retrieving the mental lexicon as it gives additional information about the meaning of the word. Poor PS might hamper the differentiation of compound words, e.g., HIGHchair versus high CHAIR, in German FÜRsorge (welfare) versus für SORge (for concern; cf. Holliman, 2016; Kitzen, 2001, as cited in Whalley \& Hansen, 2006; Wood et al., 2009). Furthermore, homophones can only be identified correctly via the correct assignment of stress, e.g., in German MOdern (molder) versus moDERN (modern), Übersetzen (cross over) versus überSETzen (translate). In these cases, problems in assigning stress correctly might lead to a conflict in the stored lexical representation of morphemes and thus slow reading and enhance reading errors (Sauter, Heller, \& Landerl, 2012).

\section{Empirical evidence}

Empirical evidence for the influence of PS on reading comes from studies comparing persons with and without dyslexia as well as from correlational studies.

\section{Group comparisons}

Several studies have found limited prosodic skills in subjects with dyslexia (Cuetos et al., 2018; Goswami et al., 2010, 2013; Leong et al., 2011). For instance, Leong et al. (2011) tested the perception of syllable stress in English-speaking adults with dyslexia. The task was to decide whether two four-syllable words had the same stress. The results showed that adults with dyslexia performed significantly worse than adults without dyslexia. Goswami et al. (2010) analysed the PS of 56 children between 8 and 15 years old with and without dyslexia. They used an adapted version of the DEEdee task, originally developed by Kitzen (2001) to measure PS on the supra-word level. In this task, children saw a picture of a familiar celebrity or a famous movie or book character. They then heard two sequences consisting of stressed and unstressed dee-syllables with the same number of total syllables. The children had to decide which DEEdee sequence matched the target phrase in terms of stress pattern, e.g., SUperMAN corresponds to DEEdeeDEE. The performance of the children with dyslexia was significantly lower than the performance of agematched children without dyslexia. Similar results in the DEEdee task were reported for 9-year-old children with dyslexia when compared to non-dyslexic children with the same reading level (Goswami et al., 2013). Moreover, studies examining more 
transparent orthographies have come to similar findings. For example, Cuetos et al. (2018) compared 32 11-year-old Spanish children with dyslexia with a group of agematched and a group of reading-matched children. Children with dyslexia exhibited lower abilities in phonological awareness (PA), rapid automatized naming and PS than age-matched children. They also showed lower abilities than the readingmatched children in one each of the PA and PS subtests.

\section{Correlational studies}

Correlational studies in languages of different orthographic depths have compared the unique impact of PS when controlling for PA. Wade-Woolley and Heggie (2016) synthesized the findings of several studies concerning the contributions of PS and PA to word and nonword reading. In five out of seven studies, PS uniquely predicted word reading above and beyond PA in regression models (Defior et al., 2012; Goswami et al., 2010; Holliman et al., 2010a, 2010b; Whalley \& Hansen, 2006). With respect to nonword reading, one out of three studies found a significant outcome for PS after controlling for PA (Jarmulowicz et al., 2007). Two studies explored the effect of PS above and beyond PA on reading composite scores, both of which reported PS to be a unique predictor (Clin et al., 2009; Holliman et al., 2008). More recent studies have delivered a similar picture. In five out of eight studies, PS uniquely predicted word reading after controlling for PA (Arciuli, 2017; Gutiérrez-Palma et al., 2016 (only for children in 3rd-5th grades); Holliman et al., 2017; Lin et al., 2018 (only for 6-year-old children); Wade-Woolley, 2016). However, Kim and Petscher (2016) could not confirm these results. In their study, PS contributed to word reading only via PA and morphological awareness. Likewise, Deacon et al. (2018) found no significant unique effects of PS on word reading. In a German study, PS had no unique effect on word and nonword reading over and above the effect of PA (Schmidt et al., 2016). Wade-Woolley (2016) also analysed nonword reading, once again finding no significant effect of PS after controlling for PA. Moreover, for the time being, the differences in the results cannot be conclusively attributed to the participants' age (at least among children) or the PS measures used (cf. Wade-Woolley \& Heggie, 2016). To exclude a possible effect of developmental aspects (e.g., different effects of PS on reading at different stages of children's development), the present study examines adult participants. While previous studies have applied different PS measures, the present study uses a PS measure on the sentence level, which has rarely been examined in German-speaking countries (Schmidt et al., 2016).

\section{The case of musicians}

An additional approach to testing the influence of PS on reading is to examine persons with extraordinary prosodic skills, i.e., musicians (e.g., Goswami, 2011). Specifically, one can test whether a particularly pronounced PS goes hand in hand with good reading (in contrast to comparisons of poor and average readers, which at best 
tells us whether there is some kind of PS deficit in dyslexic children and adults). This point is also important because it sheds light on the possible benefits of prosodic and/or musical training to prevent reading difficulties.

Although directly measured information about the PS of musicians in the German-speaking world is not available to our best knowledge (see below), it is conceivable to assume good PS because of their strong non-linguistic basic auditory processing (BAP) skills like pitch sensitivity and rhythm discrimination (e.g., Banai \& Ahissar, 2013; Deguchi et al., 2012; Micheyl, Delhommeau, Perrot, \& Oxenham, 2006; Tsang \& Conrad, 2011). In fact, musicians have been shown to outperform non-musicians in BAP tasks on a behavioural, electrophysiological and psychoacoustic basis (Banai \& Ahissar, 2013; Deguchi et al., 2012; Kraus \& Chandrasekaran, 2010; Magne, Schön, \& Besson, 2006; Micheyl et al., 2006; Nikjeh, Lister, \& Frisch, 2009; Tsang \& Conrad, 2011). Even dyslexic musicians (dyslexics generally seem to have poorer BAP skills) show better performance in rise time (which reflects the "sharpness" of a rising tone), frequency, intensity and rhythm tasks than dyslexic non-musicians and equivalent BAP skills to musicians without dyslexia (Bishop-Liebler, Welch, Huss, Thomson, \& Goswami, 2014). The study by Weiss, Granot, and Ahissar (2014) also revealed that dyslexic musicians showed comparable frequency and temporal-interval discrimination skills to musicians without dyslexia, in contrast to dyslexic non-musicians. Furthermore, BAP skills such as intensity, duration and frequency discrimination and amplitude rise time perception might be possible precursors of PS (Goswami et al., 2010, 2013; Richards \& Goswami, 2015).

Generally, BAP skills are relevant for reading. Regression analyses have shown that the perception of note duration changes in repeating rhythms predicts text reading accuracy and word reading speed (Flaugnacco et al., 2014). Furthermore, dyslexic children exhibit low performance on BAP tasks, such as tapping in time with a metronome (Thomson \& Goswami, 2008), rise time perception, pitch perception, and rhythm discrimination (Goswami, Huss, Mead, Fosker, \& Verney, 2013; Huss, Verney, Fosker, Mead, \& Goswami, 2011), as well as loudness perception (Huss et al., 2011). Thomson, Fryer, Maltby and Goswami (2006) reported similar results for adults with dyslexia. Likewise, Leong et al. (2011) also showed poorer rise time perception and pitch perception in adults with dyslexia.

However, studies comparing musicians and non-musicians in terms of reading have uncovered contradictory results. Moreno et al. (2009) assigned 32 8-year-old Portuguese non-musicians to either a musical training group or a painting training group. After 6 months, the music group but not the painting group exhibited significant improvements in word decoding and small pitch perception in speech. Similar results were found by Habib et al. (2016). They analysed the effect of a 6-week cognitive-musical training (CMT) on French dyslexic children. The results showed a significant improvement in word decoding after the CMT period, no difference after an untrained period before the CMT, and no significant decrease after an untrained period after the CMT. In addition, Bishop-Liebler et al. (2014) reported significantly higher word and nonword reading skills among dyslexic musicians compared to dyslexic non-musicians. Weiss et al. (2014) also found significantly higher pseudoword reading skills in dyslexic musicians than in dyslexic non-musicians. Furthermore, 
regression analyses have shown that music perception ability explains unique variance in early reading ability in 4- and 5-year old pre-schoolers (Anvari, Trainor, Woodside, \& Levy, 2002). In contrast, Corrigall and Trainor (2011) reported that the length of musical training among 6-9-year-old normal readers predicted reading comprehension, whereas there was no association with word decoding. No significant improvements in word or nonword decoding (but significant improvements in PA) after music instruction were found by Overy (2003) with dyslexic children (mean age 8.8 years) and Gromko (2005) with kindergarten children. These contradictory results might be explained by the type of music training, the length of training and the participants' age and reading level (Corrigall \& Trainor, 2011). Nevertheless, in her metaanalysis, Standley (2008) found a small effect size of $d=.32$ for the benefits of music instruction on reading skills. In more recent metaanalyses, Sala and Gobet (2017) reported no significant effect of music training on literacy skills (combining reading and writing), but Cooper (2019) found a small to medium effect for musical training in schoolchildren on verbal and non-verbal cognitive skills. However, when examining only studies with high methological quality, i.e., studies that took place in a lab setting, the effects become non-significant. The author concluded that "music training was ultimately a beneficial intervention but not conclusively better than other types of trainings" (Cooper, 2019, p. 14).

\section{Research questions}

Existing studies that directly emphasize the importance of musical skills for reading are limited in several respects (Anvari et al., 2002; Bishop-Liebler et al., 2014; Habib et al., 2016; Moreno et al., 2009). Corrigall and Trainor (2011) pointed out that in numerous studies, music training was close to (or combined with) reading interventions, e.g., such as teaching reading skills using song texts (e.g., Dominguez, 1991). Standley (2008) showed that the effect of a music intervention on reading was stronger for programs that comprised direct reading interventions than for those which did not. This close connection between musical training and reading activities might impede the identification of which part of the intervention had an effect on reading: the musical training or the reading part of the training.

Furthermore, to the best of our knowledge, no previous studies have compared musicians and non-musicians on more language-related PS tasks in German. German is a shallow orthography in which grapheme-phoneme correspondences are quite transparent (e.g., Seymour, Aro, \& Erskine, 2003). Due to the easiness of grapheme-phoneme mapping, it has been argued that PA might play a minor role in reading acquisition (Landerl et al., 2019; Landerl \& Wimmer, 2008; Schabmann, Schmidt, Klicpera, Gasteiger-Klicpera, \& Klingebiel, 2009; Verhagen, Aarnoutse, \& van Leeuwe, 2008). As PS might be a predictor for PA (or at least for certain components of PA) and possibly only contributes to reading via PA (Kim \& Petscher, 2016; Schmidt et al., 2016; Wade-Woolley, 2016), PS might be of only minor influence in a shallow orthography like German. Therefore, we measured PA as a control 
variable in our study to see if a possible effect of PS on reading remains after controlling for PA.

In this study, we expand knowledge about the effect of PS on reading by comparing a sample of musicians to a sample of non-musicians. As stated by WadeWoolley and Heggie (2016) "the acoustic correlates of stress are duration, amplitude and frequency" (p. 6). To analyse sensitivity to stress in spoken language, the present study uses a language-related PS measure involving real sentences and nonword sentences in German played orally. Participants had to extract the stress pattern of the sentence by perceiving syllables of different stress size (e.g., different frequency, amplitude and duration). Then, they had to select a written sentence with the same stress pattern (a detailed description of the tasks is provided below). From a theoretical perspective, a high sensitivity to these prosodic components (which we expect in the musician group) should enhance the representation of words' stress assignments in the mental lexicon, which should in turn enhance reading fluency, as prosodic information serves as an additional hint for the reader when retrieving words from the mental lexicon. Furthermore, subjects with high PS skills might find it easier to identify vowels (linked to amplitude peaks) in words (Goswami, 2003). Likewise, recognition of onset-rime boundaries in words and even non-words might be improved. This could facilitate the identification of phonological similarities to stored words and syllables and therefore enhance reading fluency. Hence, we expect higher reading fluency in the musician group.

We have two research questions:

1. Do musicians and non-musicians differ regarding PS and reading? We expect a difference in the two groups' performance on both PS and reading. As musicians show higher (pre-existing) BAP skills (e.g., Bishop-Liebler et al., 2014; Deguchi et al., 2012; Schellenberg, 2020) than non-musicians and BAP skills might be possible precursors of PS (e.g., Richards \& Goswami, 2015), we expect the musicians to be more sensitive in perceiving prosodic information than the nonmusicians.

2. Can these possible differences in PS and reading performance be attributed to a reciprocal effect of reading on PS, in the sense that long experience with fluent reading improves PS? If this is the case, we assume that the differences in PS would disappear when comparing musician and non-musician subgroups with matched reading levels.

\section{Method}

\section{Participants}

The sample comprised 60 native German-speaking university students, $30(50 \%$ males) who played a classical instrument (musicians) and 30 (50\% males) who did not play an instrument (non-musicians). Twenty-three of the musicians were recruited from the University of Cologne Symphony Orchestra, the others from different orchestras or ensembles. According to the participants' self-reported 


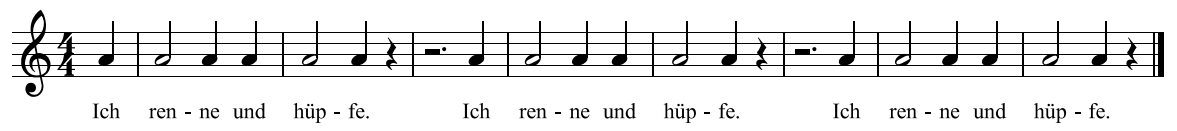

Fig. 1 The Sauter et al. (2012) piano task for the sentence Ich renne und hüpfe (I run and jump)

testimonies, all of the musicians showed especially strong musical abilities that were already apparent in early childhood. 23 had already passed the audition for the university orchestra at the time of the study. The musicians' ages ranged from 20 to 32 years $(M=24.83, S D=3.36)$, the non-musicians' ages from 18 to 31 years $(M=23.00, S D=2.64)$. This difference was significant, $t(58)=2.35, p<.05$. The participants had no known diagnosis of any kind of psychological problems or learning disability. All participants fell within the boundaries of "normal readers" according to the norms of the Salzburger Lese- und Rechtschreibtest II (Salzburg Reading and Spelling Test II, SLRT-II; Moll \& Landerl, 2010; see below for a description), with the exception of four persons in the non-musician group: one person for the word reading test, two persons for the nonword reading test, and one person for both reading tests. These persons would be classified as poor readers.

\section{Measures}

\section{Prosodic sensitivity}

According to Beyermann (2013), most German disyllabic nouns are stressed on the first syllable. In the CELEX German lemma corpus, $86 \%$ of the disyllabic nouns are trochaic and only $14 \%$ have final stress. Furthermore, German has certain rules that determine whether a syllable is stressed or unstressed. With respect to prefixes, detachable verbal particles, e.g., auf- in AUFdrehen (to turn on) are always stressed, whereas nondetachable verbal particles, e.g., ver- in verKAUfen (to sell) are unstressed (Féry, 1996). In addition, the compound stress rule (primary stress is on the first constituent element, e.g., STRAßenbahn; tram; Féry, 1996) leads to an accurate pattern in $99.5 \%$ of the disyllabic German noun compounds in CELEX (Beyermann, 2013). These regularities in the German language mean that measuring of PS on the word level would be too simple for our sample.

Since German is a stress-timed language, there is higher variability in the syllable structure (Sauter et al., 2012). Some syllables in a sentence are longer and louder in almost identical intervals, which are filled in with a variable number of unstressed syllables. Consequently, measuring PS on the sentence level requires perceiving not only stress syllables but also the entire rhythm of a sentence (Schmidt et al., 2016). Therefore, we measured PS on the sentence level rather than on the word level.

PS was measured with three tasks: The first task (piano task) was taken from Sauter et al. (2012). Participants had to match written sentences to a given sequence of piano tones of constant frequency but different length and loudness. The piano sequence was played three times from a PC, then the participants had to identify the prosodically compatible sentence out of three possible written solutions. For 
instance, the sentence Ich RENne und HÜPfe (I run and jump) would fit the sequence given in Fig. 1. Twelve piano sequences were presented (Cronbach's alpha $=.68$ ).

The second task was similar, but the participants had to match a real sentence to a sentence consisting of nonwords. The nonword sentence was played orally three times from a PC, then the participants had to identify the prosodically equivalent sentence out of three possible written solutions, e.g., MAlako TRAmelo matches FAHren wir ACHterbahn (Let's ride a roller coaster). Twelve nonword sentences were presented (Cronbach's alpha $=.87$ ).

In the third task, participants had to match a heard real sentence to another prosodically equivalent real written sentence, e.g., Ich RENne und HÜPfe (I run and jump) would match Der APfel hat WÜRmer (The apple has worms). The procedure was the same as in the second task. Twelve real sentences were presented (Cronbach's alpha $=.77$ ).

The orally presented stress pattern of the piano sequence and (nonword) sentence, respectively, had to be compared to all three written sentences to identify which could be stressed with the same pattern. For each task, the target sentences and distractors had the same number of syllables. Therefore, it was not possible to identify the solution simply by counting the syllables. In the distractor sentences, at least one unstressed syllable fell on a stressed syllable from the presented pattern, therefore allowing the distractor sentence to be excluded. Examples are provided in "Appen$\operatorname{dix}$ A". All three tasks loaded on one factor, with Cronbach's alpha $=.76$ (for the total scale; Schmidt et al., 2016).

The orally played nonword sentences (second task) and real sentences (third task) did not differ in number of syllables, sum syllable frequency, or sum biphoneme frequency, which indicates the total number of words that contain the occurred biphonemes. However, there was a difference in the number of phonemes, $t(19.37)=3.22$, $p<.01$, and number of biphonemes, $t(22)=2.89, p<.01$. This calculation is based on the sublexical measures by Hofmann, Stenneken, Conrad, and Jacobs (2007), which were derived from the German phonological word forms in CELEX. The stimuli list is shown in "Appendix B".

\section{Reading}

Reading was measured with the reading section of the Salzburger Lese- und Rechtschreibtest II (Salzburg Reading and Spelling Test II, SLRT-II) by Moll and Landerl (2010). One list of words and one list of nonwords had to be read aloud as quickly and correctly as possible within one minute. The score was the number of correctly read words, i.e., a composite score of reading speed and accuracy. Retest reliability for this test ranges from .90 to .98 (Moll \& Landerl, 2010).

\section{Phonological awareness}

PA was measured as a control variable to see if a possible effect of PS on reading still exists after controlling for PA. We used the following tasks from the German translation (Schmidt, Schabmann, \& Schiller, 2014) of the Prueba de Conciencia Fonológica (Test of Phonological Awareness) by Jiménez (1995). Segmentation: 
Participants had to name the phonemes of an orally given nonword (e.g., pok $=/ \mathrm{p} /$, $/ \mathrm{o} /, / \mathrm{k} /$ ). Deletion: Participants had to pronounce an orally presented nonword by leaving out a target phoneme (e.g., $[\mathrm{k}]$ lame=lame). Blending: The phonemes of a nonword were orally presented and the participants had to pronounce the nonword (e.g., /d/, /u/, /l/= dul). Each subtest consisted of ten items.

All tests were administered in a quiet room at the University of Cologne. All baseline items for the PS measures were presented over the PC loudspeakers. Each subject participated in an individual session, which was conducted by one of two of the authors.

\section{Data analysis}

Data analysis was undertaken using SPSS ${ }^{\circledR}$, version 24. As participants' age was correlated with reading and the piano task (Table 1), we controlled for this variable when comparing reading and PS for musicians and non-musicians.

To answer our first research question, we chose a sample of musicians who play at least one instrument on a high level. These persons should have good non-linguistic BAP skills (e.g., Banai \& Ahissar, 2013; Deguchi et al., 2012). We assumed that these can hardly be attributed to a reciprocal effect of reading on PS. However, to empirically prove this last point, we additionally conducted a subgroup analysis (second research question). If reading has no (reciprocal) influence on PS, possible differences in PS should remain when comparing groups of musicians and nonmusicians with the same reading level. Otherwise, they should vanish. Conversely, PS-matched groups of musicians and non-musicians should exhibit no difference in reading skills. To check whether possible differences in PS remained when reading was held constant, we matched participants according to their reading level using the following procedure: We matched participants whose reading sum scores differed by no more than one point. If more than one match was possible, we chose the persons who were best matched according to age and gender. Twenty persons were matched. These ten musicians did not differ from the ten non-musicians in terms of reading, sex or age (Table 2). The same procedure was followed to check whether significant reading differences could be found while holding PS constant. Here, 24 persons could be matched. The 12 musicians did not differ from the 12 non-musicians in terms of PS, sex or age (Table 2).

\section{Results}

\section{Correlation of measures}

Age was correlated with all reading measures and the piano task. Sentence and nonword sentence PS tasks, PS sum score, segmentation PA task, and PA sum score were significantly correlated with all reading measures (Table 1). In particular, a significant correlation between PS sum score and reading sum score as well as PA sum score and reading sum score were uncovered (linear regression equation: 


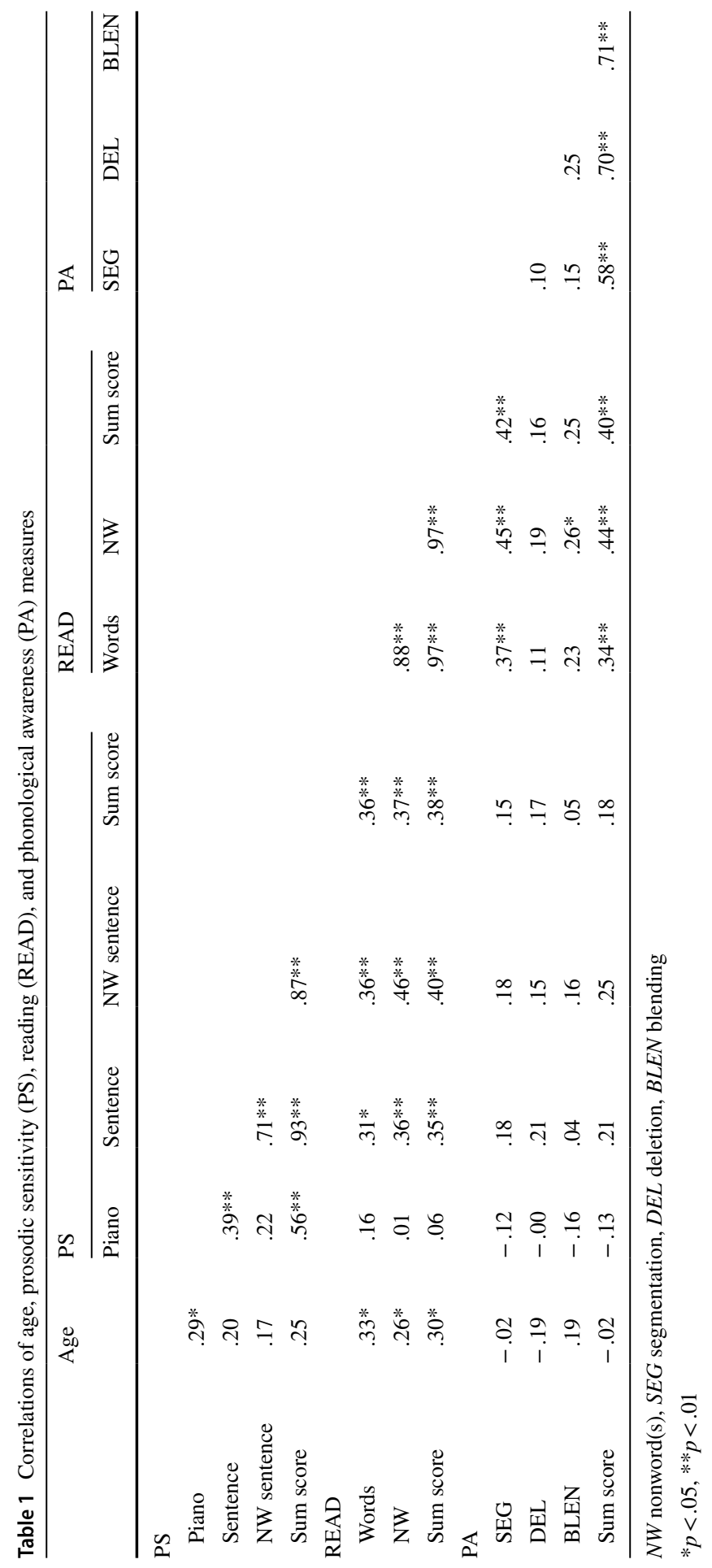


Table 2 Descriptive results of the matching criteria in the subsamples

\begin{tabular}{|c|c|c|c|c|}
\hline & \multicolumn{2}{|c|}{ Reading level-matched subsample } & \multicolumn{2}{|c|}{ PS level-matched subsample } \\
\hline & Non-musicians & Musicians & Non-musicians & Musicians \\
\hline$n$ & 10 & 10 & 12 & 12 \\
\hline Reading sum score $(S D)$ & $211.50(28.28)$ & $211.50(28.38)$ & & \\
\hline PS sum score $(S D)$ & & & $32.5(2.35)$ & $32.5(2.35)$ \\
\hline Sex (male:female) & $5: 5$ & $5: 5$ & $4: 8$ & $4: 8$ \\
\hline Age $(S D)$ & $\begin{array}{l}23.5(3.06) \\
t(18)=.80, p=.44\end{array}$ & $24.7(3.65)$ & $\begin{array}{l}23.17(2.37) \\
t(22)=.16, p=.87\end{array}$ & $23.33(2.67)$ \\
\hline
\end{tabular}

$P S$ prosodic sensitivity

Table 3 Hierarchical regression analysis predicting reading $(N=60)$

\begin{tabular}{lllll}
\hline Variable & $R^{2}$ & $\Delta R^{2}$ & \multicolumn{1}{l}{$B$} & \multicolumn{1}{l}{$\beta$} \\
\hline Step 1 & .09 & $.09^{*}$ & & \\
$\quad$ Age & & & 3.35 & $.30^{*}$ \\
Step 2 & .26 & $.17^{* *}$ & & \\
Age & & & 3.43 & $.31^{* *}$ \\
PA sum score & & & 12.75 & $.41^{* *}$ \\
Step 3 & .31 & $.06^{*}$ & & \\
Age & & & 2.73 & $.25^{*}$ \\
PA sum score & & & 11.29 & $.36^{* *}$ \\
PS sum score & & & 1.75 & $.25^{*}$ \\
\hline
\end{tabular}

$P A$ phonological awareness, $P S$ prosodic sensitivity $* p<.05, * * p<.01$

$-169+2.21 \times \mathrm{PS}+10.78 \times \mathrm{PA}=$ reading). Hierarchical regression analysis showed a unique effect of PS on reading after controlling for age and PA (Table 3). No significant correlations with reading were found for the piano task and the deletion and blending PA tasks, except for a correlation between blending and the nonword reading task (Table 1). The piano task was also insignificantly correlated with the nonword sentence PS task. There were no significant correlations between segmentation and deletion, segmentation and blending, and deletion and blending. No significant correlations with PS were found for any of the PA tasks.

\section{Differences between musicians and non-musicians}

\section{Full sample}

On average, musicians performed better on all PS tasks, reading tasks, and PA tasks than non-musicians (Table 4). To test for differences between musicians and non-musicians, we conducted MANOVAS for PS and reading scores with age as 
Table 4 Means, standard deviations, minimums, and maximums of prosodic sensitivity (PS), reading, and phonological awareness (PA) measures for musicians and non-musicians

\begin{tabular}{|c|c|c|c|c|c|c|c|c|c|c|c|}
\hline \multirow[t]{2}{*}{ Full sample } & \multicolumn{4}{|c|}{ Non-musicians } & \multicolumn{4}{|c|}{ Musicians } & \multirow{2}{*}{\multicolumn{2}{|c|}{$F(1,57)$}} & \multirow[t]{2}{*}{$\eta_{p}^{2}$} \\
\hline & $M$ & $S D$ & Min & Max & $M$ & $S D$ & Min & Max & & & \\
\hline \multicolumn{12}{|l|}{ PS } \\
\hline Piano & 11.00 & 1.49 & 5.00 & 12.00 & 11.57 & .97 & 8.00 & 12.00 & 1.32 & & .02 \\
\hline Sentence & 8.00 & 2.56 & 3.00 & 12.00 & 10.77 & 1.45 & 7.00 & 12.00 & 22.83 & $* *$ & .29 \\
\hline NW sentence & 8.40 & 2.25 & 5.00 & 12.00 & 11.13 & .90 & 9.00 & 12.00 & 34.84 & $* *$ & .38 \\
\hline Sum score & 27.40 & 4.97 & 19.00 & 35.00 & 33.47 & 2.29 & 29.00 & 36.00 & 31.00 & $* *$ & .35 \\
\hline \multicolumn{12}{|l|}{ Reading } \\
\hline Words & 122.87 & 16.81 & 89.00 & 156.00 & 137.23 & 14.74 & 101.00 & 156.00 & 8.36 & $* *$ & .13 \\
\hline NW & 75.67 & 17.76 & 41.00 & 110.00 & 91.80 & 15.56 & 64.00 & 117.00 & 10.48 & $* *$ & .16 \\
\hline \multirow[t]{2}{*}{ Sum score } & 198.53 & 33.05 & 135.00 & 266.00 & 229.03 & 29.40 & 165.00 & 271.00 & 10.20 & $* *$ & .15 \\
\hline & $M$ & $S D$ & Min & $\operatorname{Max}$ & $M$ & $S D$ & Min & $\operatorname{Max}$ & \multicolumn{2}{|c|}{$F(1,58)$} & $\eta_{p}^{2}$ \\
\hline
\end{tabular}

PA

\begin{tabular}{|c|c|c|c|c|c|c|c|c|c|c|c|}
\hline Segmentation & 9.63 & .61 & 8.00 & 10.00 & 9.90 & .31 & 9.00 & 10.00 & $4.53 *$ & $*$ & .07 \\
\hline Deletion & 9.70 & .79 & 6.00 & 10.00 & 9.97 & .18 & 9.00 & 10.00 & 3.21 & & .05 \\
\hline Blending & 9.50 & .68 & 8.00 & 10.00 & 9.87 & .35 & 9.00 & 10.00 & $6.89 *$ & $*$ & .11 \\
\hline Sum score & 28.83 & 1.37 & 25.00 & 30.00 & 29.73 & .45 & 29.00 & 30.00 & $11.74 *$ & $* *$ & .17 \\
\hline $\begin{array}{l}\text { Reading } \\
\text { level-matched } \\
\text { subsample }\end{array}$ & $M$ & $S D$ & Min & $\operatorname{Max}$ & $M$ & $S D$ & Min & $\operatorname{Max}$ & $F(1,17)$ & & $\eta_{p}^{2}$ \\
\hline
\end{tabular}

PS

\begin{tabular}{lrrrrrrrrrrr} 
Piano & 10.70 & 2.21 & 5.00 & 12.00 & 11.30 & 1.06 & 9.00 & 12.00 & .31 & & .02 \\
Sentence & 7.90 & 3.14 & 3.00 & 12.00 & 11.00 & 1.49 & 8.00 & 12.00 & 7.11 & $*$ & .30 \\
NW sentence & 9.10 & 1.85 & 6.00 & 12.00 & 11.30 & .95 & 10.00 & 12.00 & 9.69 & $* *$ & .36 \\
Sum score & 27.70 & 5.68 & 21.00 & 35.00 & 33.60 & 2.37 & 29.00 & 36.00 & 7.88 & $*$ & .32 \\
\hline $\begin{array}{l}\text { PS level- } \\
\text { matched sub- }\end{array}$ & $M$ & $S D$ & Min & Max & $M$ & SD & Min & Max & $F(1,21)$ & $\eta_{\mathrm{p}}^{2}$ \\
sample & & & & & & & & & & & \\
\hline
\end{tabular}

\begin{tabular}{lrrrrrrrrrr}
\hline Reading & & & & & & & & & & \\
Words & 122.50 & 21.22 & 89.00 & 155.00 & 129.33 & 14.37 & 101.00 & 155.00 & .80 & .04 \\
NW & 76.67 & 18.34 & 46.00 & 109.00 & 83.42 & 10.71 & 64.00 & 96.00 & 1.13 & .05 \\
Sum score & 199.17 & 38.44 & 135.00 & 255.00 & 212.75 & 24.53 & 165.00 & 251.00 & 1.00 & .05 \\
\hline
\end{tabular}

Comparisons $\left(F, \eta_{\mathrm{p}}{ }^{2}\right)$ are age-corrected for PS and reading scores

$N W$ nonword(s)

$* p<.05, * * p<.01$

a covariate, and for PA scores without a covariate. Multivariate tests revealed that musicians outperformed non-musicians on the PS tasks, $F(3,55)=12.25, p<.001$, $\eta_{\mathrm{p}}{ }^{2}=.40$, the reading tasks, $F(2,56)=5.19, p<.01, \eta_{\mathrm{p}}{ }^{2}=.16$, and the PA tasks, $F(3,56)=3.96, p<.05, \eta_{\mathrm{p}}{ }^{2}=.18$. Univariate tests showed significant differences 
for all PS, reading, and PA measures except for the piano task and the deletion PA task (Table 4). When omitting poor readers from the dataset (leading to a sample of non-musicians: $n=26$; musicians: $n=30$ ), the same pattern of results emerged (except for the segmentation PA task), piano task: $F(1,53)=1.70, p=.20, \eta_{\mathrm{p}}{ }^{2}=.03$; sentence task: $F(1,53)=22.78, p<.001, \eta_{\mathrm{p}}{ }^{2}=.30$; nonword sentence task: $F(1$, $53)=29.20, p<.001, \eta_{\mathrm{p}}{ }^{2}=.36$; PS sum score: $F(1,53)=28.56, p<.001, \eta_{\mathrm{p}}{ }^{2}=.35$; word reading: $F(1,53)=4.40, p<.05, \eta_{\mathrm{p}}{ }^{2}=.08$; nonword reading: $F(1,53)=6.15$, $p<.05, \eta_{\mathrm{p}}{ }^{2}=.10$; reading sum score: $F(1,53)=5.71, p<.05, \eta_{\mathrm{p}}{ }^{2}=.10$; segmentation: $F(1,54)=2.20, p=.14, \eta_{\mathrm{p}}{ }^{2}=.04$; deletion: $F(1,54)=3.06, p=.09, \eta_{\mathrm{p}}{ }^{2}=.05$; blending: $F(1,54)=6.33, p<.05, \eta_{\mathrm{p}}{ }^{2}=.11$; PA sum score: $F(1,54)=9.93, p<.01$, $\eta_{\mathrm{p}}^{2}=.16$.

\section{Reading level-matched sample}

The effect was less strong in this sample. When all three PS tasks were included in the equations, the multivariate test only showed a strong tendency, $F(3,15)=5.19$, $p=.05, \eta_{\mathrm{p}}{ }^{2}=.39$. However, the univariate differences between musicians and nonmusicians remained significant for the sentence and nonword sentence tasks as well as the sum score (Table 4).

\section{PS level-matched sample}

All differences in reading which were found for the total sample did not remain significant among persons with the same level of PS (Table 4).

\section{Discussion}

As previous correlational studies report inconsistent results regarding the relation between PS and reading, the present study aims to further clarify this relationship by examining subjects with excellent PS skills instead of subjects with poor reading skills (dyslexics), as has been done in previous studies (see above). As the existing literature indicates that musicians exhibit higher (pre-existing) BAP skills (e.g., Deguchi et al., 2012; Schellenberg, 2020) than non-musicians, and BAP skills could be possible precursors to PS (Goswami et al., 2010, Goswami, Mead et al., 2013; Richards \& Goswami, 2015), we expected the musicians to be more sensitive in perceiving prosodic information than the non-musicians. Hence, the goal of this study was to test whether the German PS of adult musicians is higher than among people with no musical experience, and if this is the case, whether this is associated with reading performance. Furthermore, we tried to find evidence for whether this potential effect could be attributed to a reciprocal effect of reading on PS. As most previous studies focused on English-speaking participants, the present study aims to further clarify the PS-reading relationship in a more transparent orthography.

Our results showed that, in line with our hypothesis, musicians achieved better results in reading words and nonwords as well as two of three prosodic tasks, namely the sentence and nonword sentence tasks. The mean of the musician group 
was only slightly higher for the piano task. An explanation might be that the piano task was too easy for our sample (Table 4), making ceiling effects likely. In contrast to the sentence and nonword sentence tasks, the played pattern in the piano task only requires (very low) BAP skills. It is possible that this stress pattern can be analysed and stored in working memory more easily than the stress pattern of a linguistic sequence. Thus, even the poorer PS skills of the non-musicians might suffice for this task, while differences between the two groups arise in the two linguistic PS tasks.

To check for possible reciprocal effects in our adult sample (i.e., that better word reading leads to better prosodic components on the long run, which should predominantly be the case for PS tasks that are close to reading), we compared reading levelmatched groups of musicians and non-musicians. Differences found in the whole sample remained stable for the reading level-matched groups, which makes it hardly probable that differences in PS can be attributed to differences in reading. Furthermore, comparing musician and non-musician groups with the same levels of PS did not reveal any difference in reading. Therefore, subgroup analysis seems to support our assumption that better PS (and BAP skills) can hardly be attributed to a reciprocal effect of reading on PS.

In summary, our data indicate that high PS likely facilitates reading achievement and thus that PS is not only an (additional) deficit found in dyslexics. However, it is not clear whether the high level of musical experience and high PS skills in our sample of musicians exist due to their musical training or rather due to good PS prerequisites (such as BAP skills) that existed prior to reading and prior to playing an instrument. Genetic predispositions (including, potentially, BAP skills) might influence whether or not a person learns to play an instrument (Schellenberg, 2020). An interaction of both reasons is also plausible. Hence, our results might not be attributable to the musicians' musical training per se.

The reported unique effect of PS on reading after controlling for PA (even in a shallow orthography like German) is in line with the results of previous studies conducted with children in languages of different orthographic depths (e.g., Defior et al., 2012; Holliman et al., 2017), whereas it contrasts the results by Schmidt et al. (2016) in German adult participants. However, as half the sample examined in our study is part of an extreme group, considering PS as a continuous variable might risk a biased outcome. Therefore, this result should be treated with caution. Furthermore, our results showed no significant correlation between PS and PA, arguing against a strong connection between these skills in German adults. In terms of group comparisons, musicians outperformed non-musicians in two of three PA tasks. One explanation might be the higher BAP skills assumed to be present in our musician group, which are important for the development of good PA skills (Thomson \& Goswami, 2010). However, the PA measures used in this study appeared to be way too easy for our adult sample. Therefore, the PA results should be treated with caution due to possible ceiling effects.

We measured PS using a test on the sentence level, which is seldom the case in German-speaking countries (Schmidt et al., 2016). Firstly, this was necessary because measuring PS on the word level would be too simple for our sample due to the regularities in the German language (see above; Beyermann, 2013; Féry, 1996). Secondly, results based on a PS measure on the sentence level might help clarify the 
PS-reading relationship (for German). Previous correlational studies have predominantly used PS measures on the word level. However, the results based on measures above the word level, e.g., at the phrase or sentence level (Clin et al., 2009; Goswami et al., 2010; Holliman et al., 2017; Schmidt et al., 2016; Whalley \& Hansen, 2006), are likewise contradictory. Holliman et al. (2014) considered different components of PS (stress, intonation, and timing) on different linguistic levels (word, phrase, and sentence). Their results support the assumption that PS on the word level and PS on the phrase/sentence level have different relations to reading. In the sentence-level PS measures used in this study, participants had to manage two processes. Firstly, the stress pattern of the orally presented sentence had to be analysed and stored in working memory. Unstressed and stressed syllables had to be perceived regardless of the stress produced by longer or louder articulation or pitch modulation. Secondly, the stress patterns of the written sentences had to be analysed. Stored lexical stress assignments of the printed words had to be retrieved from the mental lexicon. Additionally, in contrast to word-level measures, the relation between the words had to be considered. A lexically stressed syllable (word level) might be articulated as unstressed or less stressed in a sentence due to a certain sentence accent, whereas a lexically unstressed syllable always ${ }^{1}$ remains unstressed on the sentence level. For example, the German sentence Sie vergisst ihren Hut (She forgets her hat) may have the following stress patterns: sie verGISST ihren HUT or SIE vergisst IHren hut. The monosyllable words and lexically stressed syllables (sie, -gisst, ih-, hut) can be unstressed or less stressed on the sentence level, whereas the lexically unstressed syllables (ver-, -ren) stay unstressed in all cases. The written sentences must be compared to the orally presented stress pattern in order to determine which can be stressed identically. Thus, sentence-level PS might involve a higher process than simply retrieving lexical stress assignments.

\section{Limitations and desiderata for future research}

Since our sample of musicians exhibited a high level of musical experience, we assumed good BAP skills (and PS) prior to reading acquisition. However, adding a direct measure of BAP to this research would have been helpful to confirm the presence of good BAP skills in our musician sample. Moreover, our subgroup analysis indicated no reciprocal effect of reading on PS in the sense that long experience with fluent reading improves PS. However, it would be worthwhile to explore early BAP skills and PS prior to reading acquisition and (later) reading skills in a longitudinal design.

In terms of subgroup analysis, the sample sizes are quite small, which can result in a low test power (Cohen, 1988). Hence, the possibility cannot be completely excluded that the lack of significant difference in reading in the PS level-matched subsamples is a result of low test power.

\footnotetext{
1 Some lexically unstressed particles can be stressed on the sentence level when bearing a corrective focus, e.g., Der Laster wird BEladen und nicht ENTladen (The truck is being loaded and not unloaded, see Féry, 2011). However, this is not relevant for the type of PS measures used in this study.
} 


\section{Conclusion}

A novel finding is that PS seems to be not only a deficit in dyslexics but an advantage for reading fluency among people with high PS, as shown in a sample of musicians compared to non-musicians. Overall, when examining German-speaking adults with a language-related PS task on the sentence level, we can conclude the following: Firstly, our results support the assumption that being a musician (and thus probably having good pre-existing BAP skills) is associated with extraordinary PS skills. Secondly, our results are aligned with those of previous studies indicating a possible positive effect of PS skills on reading. These are important points due to the possible benefits of prosodic and/or musical or rather non-linguistic BAP training to prevent reading difficulties.

Funding Open Access funding enabled and organized by Projekt DEAL. We received no financial support for the research.

\section{Compliance with ethical standards}

Conflict of interest We have no conflicts of interest to disclose.

Open Access This article is licensed under a Creative Commons Attribution 4.0 International License, which permits use, sharing, adaptation, distribution and reproduction in any medium or format, as long as you give appropriate credit to the original author(s) and the source, provide a link to the Creative Commons licence, and indicate if changes were made. The images or other third party material in this article are included in the article's Creative Commons licence, unless indicated otherwise in a credit line to the material. If material is not included in the article's Creative Commons licence and your intended use is not permitted by statutory regulation or exceeds the permitted use, you will need to obtain permission directly from the copyright holder. To view a copy of this licence, visit http://creativecommons.org/licen ses/by/4.0/.

\section{Appendix A}

Examples for the prosodic sensitivity measures

$\begin{array}{llllllllll}\text { Piano task (distractors follow the principle of Sauter et al., } & \text { 2012) } & & \\ \text { Orally played piano pattern } & \bullet & \mathbf{x} & \bullet & \bullet & \mathbf{x} & \bullet & \\ \text { Fitting sentence } & \text { Ich } & \text { REN } & \text { ne } & \text { und } & \text { HÜP } & \text { fe } & \text { (I run and jump) } \\ & \bullet & \mathbf{x} & \bullet & \bullet & \mathbf{x} & \bullet & \\ \text { Distractor 1 } & \text { Sie } & \text { pro } & \text { biert } & \text { ei } & \text { nen } & \text { Keks } & \text { (She tastes a cookie) } \\ \text { Distractor 2 } & & \bullet & & & \bullet & & \\ & \text { Pflü } & \text { cken } & \text { wir } & \text { Brom } & \text { bee } & \text { ren } & \text { (Let's pick blackberries) }\end{array}$




\begin{tabular}{|c|c|c|c|c|c|c|c|}
\hline \multicolumn{8}{|l|}{ Nonword sentence task } \\
\hline \multirow[t]{2}{*}{ Orally played item } & MA & la & ko & TRA & me & lo & \\
\hline & $\mathbf{x}$ & $\bullet$ & $\bullet$ & $\mathbf{x}$ & $\bullet$ & $\bullet$ & \\
\hline \multirow[t]{2}{*}{ Fitting sentence } & FAH & ren & wir & $\mathrm{ACH}$ & ter & bahn & (Let's ride a roller coaster) \\
\hline & $\mathbf{x}$ & $\bullet$ & $\bullet$ & $\mathbf{x}$ & $\bullet$ & $\bullet$ & \\
\hline \multirow[t]{2}{*}{ Distractor 1} & Ver & giss & nicht & den & Kof & fer & (Don't forget the suitcase) \\
\hline & $\bullet$ & & & & & & \\
\hline \multirow[t]{2}{*}{ Distractor 2} & Wir & ha & ben & ge & $\mathrm{ba}$ & cken & (We baked) \\
\hline & & & & $\bullet$ & & & \\
\hline \multicolumn{8}{|l|}{ Sentence task } \\
\hline \multirow[t]{2}{*}{ Orally played item } & Ich & REN & ne & und & HÜP & $\mathrm{fe}$ & (I run and jump) \\
\hline & $\bullet$ & $\mathbf{x}$ & $\bullet$ & $\bullet$ & $\mathbf{x}$ & $\bullet$ & \\
\hline \multirow[t]{2}{*}{ Fitting sentence } & Der & $\mathrm{AP}$ & fel & hat & WÜR & mer & (The apple has worms) \\
\hline & $\bullet$ & $\mathbf{x}$ & $\bullet$ & $\bullet$ & $\mathbf{x}$ & $\bullet$ & \\
\hline \multirow[t]{2}{*}{ Distractor 1} & Sie & ver & gisst & ih & ren & Hut & (She forgets her hat) \\
\hline & & $\bullet$ & & & $\bullet$ & & \\
\hline \multirow[t]{2}{*}{ Distractor 2} & Gra & ben & wir & nach & dem & Schatz & (Let's dig for the treasure) \\
\hline & & $\bullet$ & & & & & \\
\hline
\end{tabular}

$\bullet=$ unstressed syllable; $\mathbf{x}=$ stressed syllable

\section{Appendix B}

List of nonword sentences and sentences, with international phonetic alphabet (IPA) transcriptions

\begin{tabular}{|c|c|}
\hline Nonword sentences & Sentences \\
\hline $\begin{array}{l}\text { Menri scho katschikro } \\
\text { ['menri jo: ka't] } \mathrm{Ikro}]\end{array}$ & $\begin{array}{l}\text { Oma kocht Blumenkohl } \\
\text { ['o:ma kəxt 'blu:mənko:1] }\end{array}$ \\
\hline $\begin{array}{l}\text { Terino la menta } \\
\text { [te'ri:no la 'mente] }\end{array}$ & $\begin{array}{l}\text { Sie haben gegessen } \\
\text { [zi: 'ha:bn gə'gesn] }\end{array}$ \\
\hline $\begin{array}{l}\text { Rida suke rubidan } \\
\text { ['ri:de 'zu:kə 'ru:bida:n] }\end{array}$ & $\begin{array}{l}\text { Herr Schröder isst ein Brötchen } \\
\text { [hep ' Jrø:de Ist ain 'brø:tçən] }\end{array}$ \\
\hline $\begin{array}{l}\text { Datschikro lane rema } \\
\text { [da't]rkro 'la:nə 're:me] }\end{array}$ & $\begin{array}{l}\text { Trafen sich die Reisenden } \\
\text { ['tra:fn zıç di: 'raizndn] }\end{array}$ \\
\hline $\begin{array}{l}\text { Wade tale wide tede } \\
\text { ['va:də 'ta:lə 'vi:də 'te:də] }\end{array}$ & $\begin{array}{l}\text { Du siehst mich wieder mal nicht an } \\
\text { [du: zi:st miç 'vi:de ma:l niçt an] }\end{array}$ \\
\hline $\begin{array}{l}\text { Newada tilade } \\
\text { [ne'va:de ti'la:də] }\end{array}$ & 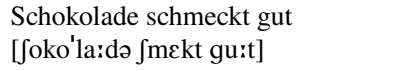 \\
\hline $\begin{array}{l}\text { Tare rume lo } \\
\text { ['ta:rə 'ru:mə lo:] }\end{array}$ & $\begin{array}{l}\text { Kathrin, komm mal her } \\
\text { ['katri:n kom ma:1 he:pe] }\end{array}$ \\
\hline $\begin{array}{l}\text { Denirele dara troll } \\
\text { [də'ni:rələ 'da:re tro:l] }\end{array}$ & $\begin{array}{l}\text { Tante Frieda mag Kuchen } \\
\text { ['tantə 'fri:da ma:k 'ku:xn] }\end{array}$ \\
\hline $\begin{array}{l}\text { Dewanare til } \\
\text { [də'va:narə ti:l] }\end{array}$ & $\begin{array}{l}\text { Trink deine Limo } \\
\text { [trınk 'dainə 'lımo] }\end{array}$ \\
\hline
\end{tabular}




\begin{tabular}{|c|c|c|c|c|}
\hline \multicolumn{3}{|l|}{ Nonword sentences } & \multicolumn{2}{|l|}{ Sentences } \\
\hline $\begin{array}{l}\text { Tedola rewe tschiko } \\
\text { [te'do:le 're:vo 't] [rko] }\end{array}$ & & & $\begin{array}{l}\text { Schneckenhäl } \\
\text { ['Jnzknḩyzyze }\end{array}$ & \\
\hline $\begin{array}{l}\text { Rame dane wila } \\
\text { ['ra:mə 'da:nə 'vi:le] }\end{array}$ & & & $\begin{array}{l}\text { Bewache dein } \\
\text { [bo'vaxə 'dain }\end{array}$ & \\
\hline \multirow[t]{2}{*}{$\begin{array}{l}\text { Dadele diri wane } \\
\text { ['da:dələ 'di:ri 'va:nə] }\end{array}$} & & & \multicolumn{2}{|c|}{ 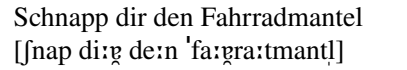 } \\
\hline & $M$ & $S D$ & $M$ & $S D$ \\
\hline$n$ phonemes $^{\mathrm{a}}$ & 14.33 & 2.27 & 18.08 & 3.34 \\
\hline$n$ biphonemes $^{\mathrm{a}}$ & 11.42 & 2.07 & 14.25 & 2.70 \\
\hline$n$ syllables & 6.42 & .90 & 6.42 & .90 \\
\hline $\mathrm{MSBF}^{\mathrm{a}}$ & 15,575 & 24,831 & 21,114 & 31,272 \\
\hline $\mathrm{MSSF}^{\mathrm{a}}$ & 3073 & 2925 & 3119 & 6200 \\
\hline
\end{tabular}

$M S B F$ mean sum biphoneme frequency, MSSF mean sum syllable frequency

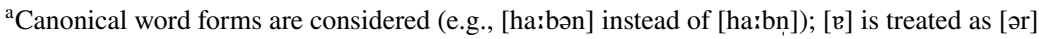

\section{References}

Anvari, S. H., Trainor, L. J., Woodside, J., \& Levy, B. A. (2002). Relations among musical skills, phonological processing, and early reading ability in preschool children. Journal of Experimental Child Psychology, 83, 111-130. https://doi.org/10.1016/S0022-0965(02)00124-8.

Arciuli, J. (2017). The relationship between children's sensitivity to dominant and non-dominant patterns of lexical stress and reading accuracy. Journal of Experimental Child Psychology, 157, 1-13. https://doi.org/10.1016/j.jecp.2016.11.016.

Banai, K., \& Ahissar, M. (2013). Musical experience, auditory perception and reading-related skills in children. PLoS ONE, 8, e75876. https://doi.org/10.1371/journal.pone.0075876.

Beyermann, S. (2013). Orthographic cues to word stress in German: Word endings and number of final consonant letters. Written Language \& Literacy, 16, 32-59. https://doi.org/10.1075/ wll.16.1.02bey.

Bishop-Liebler, P., Welch, G., Huss, M., Thomson, J. M., \& Goswami, U. (2014). Auditory temporal processing skills in musicians with dyslexia. Dyslexia: An International Journal of Research and Practice, 20, 261-279. https://doi.org/10.1002/dys.1479.

Brown, G. D. A., \& Loosemore, R. P. W. (1994). Computational approaches to normal and impaired spelling. In G. D. A. Brown \& N. C. Ellis (Eds.), Handbook of spelling: Theory, process and intervention (pp. 319-335). Chichester: Wiley.

Chiat, S. (1983). Why Mikey's right and my key's wrong: The significance of stress and word boundaries in a child's output system. Cognition: International Journal of Cognitive Science, 14, 275-300. https://doi.org/10.1016/0010-0277(83)90007-0.

Clin, E., Wade-Woolley, L., \& Heggie, L. (2009). Prosodic sensitivity and morphological awareness in children's reading. Journal of Experimental Child Psychology, 104, 197-213. https://doi. org/10.1016/j.jecp.2009.05.005.

Cohen, J. (1988). Statistical power analysis for the behavioral sciences (2nd ed.). Hillsdale, NJ: Lawrence Erlbaum Associates.

Cooper, P. K. (2019). It's all in your head: A meta-analysis on the effects of music training on cognitive measures in schoolchildren. International Journal of Music Education. https://doi. org/10.1177/0255761419881495. 
Corrigall, K. A., \& Trainor, L. J. (2011). Associations between length of music training and reading skills in children. Music Perception: An Interdisciplinary Journal, 29, 147-155. https://doi.org/10.1525/ mp.2011.29.2.147.

Cuetos, F., Martínez-García, C., \& Suárez-Coalla, P. (2018). Prosodic perception problems in Spanish dyslexia. Scientific Studies of Reading, 22, 41-54. https://doi.org/10.1080/10888438.2017.1359273.

Cutler, A., \& Norris, D. (1988). The role of strong syllables in segmentation for lexical access. Journal of Experimental Psychology: Human Perception and Performance, 14, 113-121. https://doi. org/10.1037/0096-1523.14.1.113.

Deacon, S. H., Holliman, A. J., Dobson, G. J., \& Harrison, E. C. J. (2018). Assessing direct contributions of morphological awareness and prosodic sensitivity to children's word reading and reading comprehension. Scientific Studies of Reading, 22, 527-534. https://doi.org/10.1080/10888438.2018.14833 76.

Defior, S., Gutiérrez-Palma, N., \& Cano-Marín, M. J. (2012). Prosodic awareness skills and literacy acquisition in Spanish. Journal of Psycholinguistic Research, 41, 285-294. https://doi.org/10.1007/ s10936-011-9192-0.

Deguchi, C., Boureux, M., Sarlo, M., Besson, M., Grassi, M., Schön, D., et al. (2012). Sentence pitch change detection in the native and unfamiliar language in musicians and non-musicians: Behavioral, electrophysiological and psychoacoustic study. Brain Research, 1455, 75-89. https://doi. org/10.1016/j.brainres.2012.03.034.

Dominguez, D. (1991). Developing language through a musical program and its effect on the reading achievement of Spanish speaking migrant children (Doctoral dissertation, Western Michigan University). Retrieved January 8, 2020, from https://scholarworks.wmich.edu/dissertations/2019.

Féry, C. (1996). German foot and word stress in OT. In P. Bye, O. Lorentz, \& C. Rice (Eds.), Papers from the 2nd workshop on comparative Germanic phonology (pp. 63-96). Troms $\varnothing$ : Universitet i Troms $\varnothing$. Institutt for språk og litteratur.

Féry, C. (2011). German sentence accents and embedded prosodic phrases. Lingua: An International Review of General Linguistics, 121, 1906-1922. https://doi.org/10.1016/j.lingua.2011.07.005.

Flaugnacco, E., Lopez, L., Terribili, C., Zoia, S., Buda, S., Tilli, S., et al. (2014). Rhythm perception and production predict reading abilities in developmental dyslexia. Frontiers in Human Neuroscience, 8, 392. https://doi.org/10.3389/fnhum.2014.00392.

Goswami, U. (2003). How to beat dyslexia: The broadbent lecture 2003. The Psychologist, 16, 462-465. https://thepsychologist.bps.org.uk/volume-16/edition-9/how-beat-dyslexia.

Goswami, U. (2011). A temporal sampling framework for developmental dyslexia. Trends in Cognitive Sciences, 15, 3-10. https://doi.org/10.1016/j.tics.2010.10.001.

Goswami, U., Gerson, D., \& Astruc, L. (2010). Amplitude envelope perception, phonology and prosodic sensitivity in children with developmental dyslexia. Reading and Writing: An Interdisciplinary Journal, 23, 995-1019. https://doi.org/10.1007/s11145-009-9186-6.

Goswami, U., Huss, M., Mead, N., Fosker, T., \& Verney, J. P. (2013). Perception of patterns of musical beat distribution in phonological developmental dyslexia: Significant longitudinal relations with word reading and reading comprehension. Cortex: A Journal devoted to the Study of the Nervous System and Behavior, 49, 1363-1376. https://doi.org/10.1016/j.cortex.2012.05.005.

Goswami, U., Mead, N., Fosker, T., Huss, M., Barnes, L., \& Leong, V. (2013). Impaired perception of syllable stress in children with dyslexia: A longitudinal study. Journal of Memory and Language, 69, 1-17. https://doi.org/10.1016/j.jml.2013.03.001.

Goswami, U., Thomson, J., Richardson, U., Stainthorp, R., Hughes, D., Rosen, S., et al. (2002). Amplitude envelope onsets and developmental dyslexia: A new hypothesis. Proceedings of the National Academy of Sciences of the United States of America, 99, 10911-10916. https://doi.org/10.1073/ pnas. 122368599.

Gromko, J. E. (2005). The effect of music instruction on phonemic awareness in beginning readers. Journal of Research in Music Education, 53, 199-209. https://doi.org/10.1177/002242940505300302.

Gutiérrez-Palma, N., Defior, S., Jiménez-Fernández, G., Serrano, F., \& González-Trujillo, M. C. (2016). Lexical stress awareness and orthographic stress in Spanish. Learning and Individual Differences: Journal of Psychology and Education, 45, 144-150. https://doi.org/10.1016/j.lindif.2015.11.026.

Habib, M., Lardy, C., Desiles, T., Commeiras, C., Chobert, J., \& Besson, M. (2016). Music and dyslexia: A new musical training method to improve reading and related disorders. Frontiers in Psychology, 7, 26. https://doi.org/10.3389/fpsyg.2016.00026. 
Harrison, E., \& Wood, C. (2016). Towards a speech rhythm-based reading intervention. In J. Thomson \& L. Jarmulowicz (Eds.), Linguistic rhythm and literacy (pp. 77-98). Amsterdam: John Benjamins Publishing Company.

Hofmann, M. J., Stenneken, P., Conrad, M., \& Jacobs, A. M. (2007). Sublexical frequency measures for orthographic and phonological units in German. Behavior Research Methods, 39, 620-629. https:// doi.org/10.3758/BF03193034.

Holliman, A. J. (2016). Suprasegmental phonology and early reading development. In J. Thomson \& L. Jarmulowicz (Eds.), Linguistic rhythm and literacy (pp. 25-50). Amsterdam: John Benjamins Publishing Company.

Holliman, A. J., Critten, S., Lawrence, T., Harrison, E., Wood, C., \& Hughes, D. (2014a). Modeling the relationship between prosodic sensitivity and early literacy. Reading Research Quarterly, 49, 469-482. https://doi.org/10.1002/rrq.82.

Holliman, A. J., Gutiérrez-Palma, N., Critten, S., Wood, C., Cunnane, H., \& Pillinger, C. (2017). Examining the independent contribution of prosodic sensitivity to word reading and spelling in early readers. Reading and Writing: An Interdisciplinary Journal, 30, 509-521. https://doi.org/10.1007/s1114 5-016-9687-z.

Holliman, A. J., Williams, G. J., Mundy, I. R., Wood, C., Hart, L., \& Waldron, S. (2014b). Beginning to disentangle the prosody-literacy relationship: A multi-component measure of prosodic sensitivity. Reading and Writing: An Interdisciplinary Journal, 27, 255-266. https://doi.org/10.1007/s1114 5-013-9443-6.

Holliman, A. J., Wood, C., \& Sheehy, K. (2008). Sensitivity to speech rhythm explains individual differences in reading ability independently of phonological awareness. British Journal of Developmental Psychology, 26, 357-367. https://doi.org/10.1348/026151007X241623.

Holliman, A. J., Wood, C., \& Sheehy, K. (2010a). The contribution of sensitivity to speech rhythm and non-speech rhythm to early reading development. Educational Psychology: An International Journal of Experimental Educational Psychology, 30, 247-267. https://doi.org/10.1080/0144341090 3560922 .

Holliman, A. J., Wood, C., \& Sheehy, K. (2010b). Does speech rhythm sensitivity predict children's reading ability 1 year later? Journal of Educational Psychology, 102, 356-366. https://doi.org/10.1037/ a0018049.

Holliman, A. J., Wood, C., \& Sheehy, K. (2012). A cross-sectional study of prosodic sensitivity and reading difficulties. Journal of Research in Reading, 35, 32-48. https://doi.org/10.111 1/j.1467-9817.2010.01459.x.

Huss, M., Verney, J. P., Fosker, T., Mead, N., \& Goswami, U. (2011). Music, rhythm, rise time perception and developmental dyslexia: Perception of musical meter predicts reading and phonology. Cortex: A Journal devoted to the Study of the Nervous System and Behavior, 47, 674-689. https://doi. org/10.1016/j.cortex.2010.07.010.

Jackson, N. E., \& Coltheart, M. (2001). Routes to reading success and failure. New York, NY: Psychology Press.

Jarmulowicz, L., Taran, V. L., \& Hay, S. E. (2007). Third graders' metalinguistic skills, reading skills, and stress production in derived English words. Journal of Speech, Language, and Hearing Research, 50, 1593-1605. https://doi.org/10.1044/1092-4388(2007/107).

Jiménez, J. F. (1995). Prueba de Conciencia Fonológica [Test of Phonological Awareness]. In J. Jiménez \& M. Oritz (Eds.), Conciencia fonológica y aprendizaje de la lectura: Teoria, evaluación e intervención (pp. 74-78). Madrid: Síntesis.

Kim, Y.-S. G., \& Petscher, Y. (2016). Prosodic sensitivity and reading: An investigation of pathways of relations using a latent variable approach. Journal of Educational Psychology, 108, 630-645. https ://doi.org/10.1037/edu0000078.

Kitzen, K. R. (2001). Prosodic sensitivity, morphological ability and reading ability in young adults with and without childhood histories of reading difficulty [Doctoral dissertation, Columbia University]. ProQuest Dissertations \& Theses A\&I.

Kraus, N., \& Chandrasekaran, B. (2010). Music training for the development of auditory skills. Nature Reviews Neuroscience, 11, 599-605. https://doi.org/10.1038/nrn2882.

Landerl, K., Freudenthaler, H. H., Heene, M., De Jong, P. F., Desrochers, A., Manolitsis, G., et al. (2019). Phonological awareness and rapid automatized naming as longitudinal predictors of reading in five alphabetic orthographies with varying degrees of consistency. Scientific Studies of Reading, 23, 220-234. https://doi.org/10.1080/10888438.2018.1510936. 
Landerl, K., \& Wimmer, H. (2008). Development of word reading fluency and spelling in a consistent orthography: An 8-year follow-up. Journal of Educational Psychology, 100, 150-161. https://doi. org/10.1037/0022-0663.100.1.150.

Leong, V., Hämäläinen, J., Soltész, F., \& Goswami, U. (2011). Rise time perception and detection of syllable stress in adults with developmental dyslexia. Journal of Memory and Language, 64, 59-73. https://doi.org/10.1016/j.jml.2010.09.003.

Lin, C. Y., Wang, M., Newman, R. S., \& Li, C. (2018). The development of stress sensitivity and its contribution to word reading in school-aged children. Journal of Research in Reading, 41, 259-277. https://doi.org/10.1111/1467-9817.12094.

Magne, C., Schön, D., \& Besson, M. (2006). Musician children detect pitch violations in both music and language better than nonmusician children: Behavioral and electrophysiological approaches. Journal of Cognitive Neuroscience, 18, 199-211. https://doi.org/10.1162/jocn.2006.18.2.199.

Micheyl, C., Delhommeau, K., Perrot, X., \& Oxenham, A. J. (2006). Influence of musical and psychoacoustical training on pitch discrimination. Hearing Research, 219, 36-47. https://doi.org/10.1016/j. heares.2006.05.004.

Moll, K., \& Landerl, K. (2010). SLRT-II: Lese- und Rechtschreibtest; Weiterentwicklung des Salzburger Lese- und Rechtschreibtests (SLRT) [SLRT-II: Reading and Spelling Test] (2nd ed.). Göttingen: Hogrefe.

Moreno, S., Marques, C., Santos, A., Santos, M., Castro, S. L., \& Besson, M. (2009). Musical training influences linguistic abilities in 8-year-old children: More evidence for brain plasticity. Cerebral Cortex, 19, 712-723. https://doi.org/10.1093/cercor/bhn120.

Nikjeh, D. A., Lister, J. J., \& Frisch, S. A. (2009). Preattentive cortical-evoked responses to pure tones, harmonic tones, and speech: Influence of music training. Ear and Hearing: The Official Journal of the American Auditory Society, 30, 432-446. https://doi.org/10.1097/AUD.0b013e3181a61bf2.

Overy, K. (2003). Dyslexia and music: From timing deficits to musical intervention. Annals of the New York Academy of Sciences, 999, 497-505. https://doi.org/10.1196/annals.1284.060.

Richards, S., \& Goswami, U. (2015). Auditory processing in specific language impairment (SLI): Relations with the perception of lexical and phrasal stress. Journal of Speech, Language, and Hearing Research, 58, 1292-1305. https://doi.org/10.1044/2015_JSLHR-L-13-0306.

Sala, G., \& Gobet, F. (2017). When the music's over. Does musical skill transfer to children's and young adolescents' cognitive and academic skills? A meta-analysis. Educational Research Review, 20, 55-67. https://doi.org/10.1016/j.edurev.2016.11.005.

Sauter, K., Heller, J., \& Landerl, K. (2012). Sprachrhythmus und Schriftspracherwerb [Speech rhythm and written language acquisition]. Lernen und Lernstörungen, 1, 225-239. https://doi.org/10.1024/22350977/a000023.

Schabmann, A., Schmidt, B. M., Klicpera, C., Gasteiger-Klicpera, B., \& Klingebiel, K. (2009). Does systematic reading instruction impede prediction of reading a shallow orthography? Psychology Science Quarterly, 51, 315-338.

Schellenberg, E. G. (2020). Music training, individual differences, and plasticity. In M. S. C. Thomas, D. Mareschal, \& I. Dumontheil (Eds.), Educational neuroscience: Development across the lifespan (pp. 413-439). New York, NY: Routledge.

Schmidt, B. M., Breuer-Küppers, P., Göntgen, S., \& Schabmann, A. (2016). Prosodische Sensitivität und Phonologische Bewusstheit bei schwachen und durchschnittlichen erwachsenen deutschen Lesern [Prosodic sensitivity and phonological awareness among weak and average adult German readers]. Heilpädagogische Forschung: Zeitschrift für Pädagogik und Psychologie bei Behinderungen, 42, 24-32.

Schmidt, B. M., Schabmann, A., \& Schiller, B. (2014). Kaum Defizite in der Phonologischen Bewusstheit bei leseschwachen deutschsprachigen Erwachsenen [No deficits in phonological awareness among struggling German adult readers]. Heilpädagogische Forschung: Zeitschrift für Pädagogik und Psychologie bei Behinderungen, 40, 49-59.

Scott, S. K. (1998). The point of P-centres. Psychological Research: An International Journal of Perception, Attention, Memory, and Action, 61, 4-11. https://doi.org/10.1007/PL00008162.

Seymour, P. H. K., Aro, M., \& Erskine, J. M. (2003). Foundation literacy acquisition in European orthographies. British Journal of Psychology, 94, 143-174. https://doi.org/10.1348/000712603321661859.

Standley, J. M. (2008). Does music instruction help children learn to read? Evidence of a meta-analysis. Update: Applications of Research in Music Education, 27, 17-32. https://doi.org/10.1177/87551 23308322270 . 
Thomson, J. M., Fryer, B., Maltby, J., \& Goswami, U. (2006). Auditory and motor rhythm awareness in adults with dyslexia. Journal of Research in Reading, 29, 334-348. https://doi.org/10.111 1/j.1467-9817.2006.00312.x.

Thomson, J. M., \& Goswami, U. (2008). Rhythmic processing in children with developmental dyslexia: Auditory and motor rhythms link to reading and spelling. Journal of Physiology-Paris: An International Journal for the Neurosciences, 102, 120-129. https://doi.org/10.1016/j.jphysparis 2008.03.007.

Thomson, J. M., \& Goswami, U. (2010). Learning novel phonological representations in developmental dyslexia: Associations with basic auditory processing of rise time and phonological awareness. Reading and Writing: An Interdisciplinary Journal, 23, 453-473. https://doi.org/10.1007/s1114 5-009-9167-9.

Tsang, C. D., \& Conrad, N. J. (2011). Music training and reading readiness. Music Perception: An Interdisciplinary Journal, 29, 157-163. https://doi.org/10.1525/mp.2011.29.2.157.

Verhagen, W., Aarnoutse, C., \& van Leeuwe, J. (2008). Phonological awareness and naming speed in the prediction of Dutch children's word recognition. Scientific Studies of Reading, 12, 301-324. https:// doi.org/10.1080/10888430802132030.

Wade-Woolley, L. (2016). Prosodic and phonemic awareness in children's reading of long and short words. Reading and Writing: An Interdisciplinary Journal, 29, 371-382. https://doi.org/10.1007/ s11145-015-9600-1.

Wade-Woolley, L., \& Heggie, L. (2016). The contributions of prosodic and phonological awareness to reading: A review. In J. Thomson \& L. Jarmulowicz (Eds.), Linguistic rhythm and literacy (pp. 3-24). Amsterdam: John Benjamins Publishing Company.

Weiss, A. H., Granot, R. Y., \& Ahissar, M. (2014). The enigma of dyslexic musicians. Neuropsychologia: An International Journal in Behavioural and Cognitive Neuroscience, 54, 28-40. https://doi. org/10.1016/j.neuropsychologia.2013.12.009.

Whalley, K., \& Hansen, J. (2006). The role of prosodic sensitivity in children's reading development. Journal of Research in Reading, 29, 288-303. https://doi.org/10.1111/j.1467-9817.2006.00309.x.

Wood, C., Wade-Woolley, L., \& Holliman, A. J. (2009). Phonological awareness: Beyond phonemes. In C. Wood \& V. Connelly (Eds.), Contemporary perspectives on reading and spelling (pp. 7-23). London: Routledge.

Publisher's Note Springer Nature remains neutral with regard to jurisdictional claims in published maps and institutional affiliations. 